\title{
Alzheimer Hastalı̆̆ı Bilgilendirmesinde Kaynak Olarak YouTube Videolarının İncelenmesi
}

\author{
Analysing YouTube Videos as a Source for Alzheimer's Disease \\ Information
}

\author{
Mehmet Tayfun KAŞIKCI ${ }^{1}$, Sinan YILDIRIM ${ }^{2}$ \\ ${ }^{1}$ Mehmet Akif ERSOY Devlet Hastanesi, Nöroloji Kliniği, Çanakkale \\ ${ }^{2}$ Mehmet Akif ERSOY Devlet Hastanesi, Acil Servisi, Çanakkale
}

\begin{abstract}
$\overline{\mathbf{O z}}$
Alzheimer Hastalığı (AH) belirli bir nöropatolojiye dayanan ve başlangıcı olan, zaman içerisinde yaşlanmayla birlikte kognitif ve işlevsel kayıp ile seyreden bir hastalığı ifade eder. Demansın en yaygın nedeni olan Alzheimer hastalığ büyük etkileri olan, büyüyen bir küresel sağlık sorunudur. Araştırmalar özellikle YouTube ve benzeri kanalların insanların sağlık ilişkili bilgi alışverişinde önemli bir yeri olduğunu göstermektedir. Araştırma için YouTube sayfasında arama çubuğuna Türkçe videolar için “Alzheimer Hastalığı” ve İngilizce videolar için “Alzheimer's Disease” yazıldı. Türkçe ve İngilizce olarak yayınlanan toplam 120 video iki araştırmacı tarafından izlendi ve değerlendirildi. Videonun yüklenme tarihi, süresi, görüntülenme sayısı, beğenme ve beğenmeme sayısı, videoyu yükleyen, yorum sayısı kaydedildi. Videonun kalitesi ve içeriği Video Power Index (VPI), modifiye DISCERN ölçeği ve Global Quality Scale (GQS) ölçeği kullanılarak değerlendirildi. Videoların kalitesini karşılaştırdığımız ölçeklerde VPI $(\mathrm{p}<0.001)$, GQS $(\mathrm{p}<0.001)$ ve modifiye DISCERN ölçeği $(\mathrm{p}<0.001)$ puanlarının İngilizce yayınlanan videolarda Türkçe yayınlanan videolara göre anlamlı derecede yüksek olduğu tespit edildi. Videoları yayınlayan kaynakları kendi aralarında karşılaştırdığımızda GQS ( $\mathrm{p}=0.008)$ ve Modifìye DISCERN $(\mathrm{p}=0.023)$ puanlarında anlamlı fark olduğunu tespit ettik. Alzheimer Hastalığı ile ilgili olarak hazırlanan ve internet ortamında halka açık olarak Türkçe yayınlanan bilgilendirici videoların konusunda uzman hekimlerin yanı sıra akademik kurumlar tarafından toplumun beklentisini karşılayan, özellikle hasta ve yakınlarının tecrübelerini içerecek şekilde hazırlanmasının daha faydalı olacağını düşünmekteyiz.

Anahtar Kelimeler: Alzheimer Hastalığı, Alzheimer Hastalığı YouTube, YouTube
\end{abstract}

\section{Giriş}

Alzheimer Hastalığı (AH) ilk defa 1906 yılında Alois Alzheimer tarafından tanımlanmıştır. Belirli bir nöropatolojiye dayanan ve başlangıcı olan, zaman içerisinde yaşlanmayla birlikte kognitif ve işlevsel kayıp ile seyreden bir hastalığı ifade eder (1). Demansın en yaygın nedeni olan Alzheimer hastalığı, bireyler ve toplum için büyük etkileri olan, büyüyen bir küresel sağlık sorunudur (2). Alzheimer Hastalığı (AH) semptom ve bulguları bellek

\begin{tabular}{|c|c|}
\hline $\begin{array}{l}\text { Mehmet Tayfun KAŞIKCI } \\
\text { Sinan YILDIRIM }\end{array}$ & $\begin{array}{l}\text { ORCID No } \\
0000-0001-7256-6191 \\
0000-0001-8191-168 X\end{array}$ \\
\hline $\begin{array}{l}\text { Başvuru Tarihi / Received: } \\
\text { Kabul Tarihi / Accepted : }\end{array}$ & $\begin{array}{l}27.09 .2021 \\
23.11 .2021\end{array}$ \\
\hline $\begin{array}{l}\text { Adres / Correspondence : } \\
\text { Mehmet Akif ERSOY I } \\
\text { Çanakkale }\end{array}$ & $\begin{array}{l}\text { Mehmet Tayfun KAŞIKCI } \\
\text { et Hastanesi, Nöroloji Kliniği, }\end{array}$ \\
\hline e-posta / e-mail : & dr_mtayfun@yahoo.com \\
\hline
\end{tabular}

\begin{abstract}
Alzheimer's Disease (AD) is the most common cause of dementia, is a growing global health problem for individuals and society. Research indicates that YouTube and similar channels have an important place in people's health-related information exchange. For the research, " Alzheimer Hastalı̆ğ" for Turkish videos and "Alzheimer's Disease" for English videos were analysed on the YouTube page. A total of 120 videos were evaluated. The upload date and duration of the video, the number of views, the number of likes and dislikes, the number of uploaders and comments were recorded. The quality and content of the video was assessed using the Video Power Index (VPI), modified DISCERN scale, and Global Quality Scale (GQS). In the scales in which we compared the quality of the videos, it was found that the VPI $(\mathrm{p}<0.001)$, GQS $(\mathrm{p}<0.001)$ and modified DISCERN scale $(\mathrm{p}<0.001)$ scores were significantly higher in the videos published in English compared to the videos published in Turkish. When we compared the sources that published the videos among themselves, we found that there was a significant difference in the GQS $(\mathrm{p}=0.008)$ and Modified DISCERN ( $\mathrm{p}=0.023$ ) scores. We think that it would be more beneficial to prepare informative videos about Alzheimer's Disease, which are published in Turkish on the internet, by academic institutions as well as specialist physicians, in a way that meets the expectations of the society and includes the experiences of patients and their relatives.
\end{abstract}

Keywords: Alzheimer's Disease, Alzheimer's Disease YouTube, YouTube

kaybının ön planda olduğu konuşma, yutma ve yürüme güçlüğünün yanısıra zaman içerisinde gelişen dezoryantasyon, iletişim, yargılama bozukluğu ve davranış değişiklikleridir (3). Hastalığın patolojisini ekstrasellüler $\beta$-amiloid plaklar ile nöronal sitoplazmada fosforile Tau kaynaklı nörofibriler yumaklar oluşturur (4). Bu patolojik yapıların rol oynadığı süreç bellek işlevleri, öğrenme ve diğer kognitif işlevlerde görev alan nöron ve sinapslarda hasara neden olarak hastalığ 1 ortaya çıkarır (5). Alzheimer Hastalığı (AH) için risk faktörleri; yaş, ailede hastalık öyküsü, genetik, ağır kafa travması, kardiyovasküler hastalık (yoğun sigara ve alkol kullanımı, obezite, diabetes mellitus, yüksek kan basıncı, dislipidemi), işitme kaybı, stres, tedavi edilmemiş depresyon, yetersiz uyku, sosyal izolasyon (eşini kaybetmiş veya ayrılmış olmak), sedanter yaşam tarzıdır (6,7). Kardiyovasküler risk faktörlerinin azaltılmasıyla, sağlıklı beslenme, düzenli egzersiz, sosyal aktivitelere katılım, kognitif işlevleri artıracak zihinsel aktivitelerin (satranç, 
hobiler, öğrenme vb.) yapılması kognitif yıkım riskini azaltmaktadır $(3,8,9)$.

Araştırmalar kronik hastalığı olan insanların ve yakınlarının sağlık durumlarını yönetmek için internet tabanlı kaynaklara giderek daha fazla güvendiğini, özellikle YouTube ve benzeri kanalların insanların sağlık ilişkili bilgi alışverişinde önemli bir yeri olduğunu göstermektedir (10). Bununla birlikte, sağlık hizmeti sağlayıcıları ve devlet kurumları bu platformda mevcut olan bilgilerin doğruluğu ve kalitesi konusunda endişelerini dile getirmektedir (11).

Literatürde Alzheimer Hastalığı ile ilişkili bilgi içeren YouTube videolarının kalitesini değerlendiren çalışmaların az sayıda olduğu, Türkiye'de ise yayınlanan bir çalışmanın olmadığını gördük. Çalışmamızda Alzheimer Hastalı̆̆ hakkında bilgi veren Türkçe ve İngilizce YouTube videolarının niteliklerini ve izleyenler için ne kadar faydalı olduğunu değerlendirmeyi amaçladık.

\section{Gereç ve Yöntem}

Araştırma için 30.08.2021 tarihinde, arama geçmişi silinerek YouTube sayfasında arama çubuğuna Türkçe videolar için "Alzheimer Hastalığı” ve İngilizce videolar için “Alzheimer's Disease" yazıldı. İnternet arama motorları üzerine yapılan çalışmalarda, kullanıcıların \%90'dan fazlasının arama sonucu için ilk 3 sayfayı değerlendirmesinden dolayı çalışmamızda ilk 3 sayfada yer alan 60 video değerlendirildi (11). Tamamen veya kısmen alıntı yapılarak tekrarlanan videolar değerlendirmeye alınmadı, bu şekilde yayınlanan videolardan yayınlanma tarihi önce olan video değerlendirildi. Çalışmada Türkçe ve İngilizce olarak yayınlanan videolar iki araştırmacı tarafından izlendi ve değerlendirildi. Videonun yüklenme tarihi, süresi, görüntülenme sayısı, beğenme ve beğenmeme sayısı, videoyu yükleyen (1.Sağlık kuruluşu, 2. İlaç firması, 3. Web sitesi, 4. TV kanalı, 5.Sağlık profesyoneli), yorum sayısı kaydedildi. Beğenme oranı (Beğenme sayısı X 100 / (Beğenme sayısı + Beğenmeme say1s1)), izlenme oranı ((İzlenme sayısı / Günler)) ve bağlantılı olarak Video Power Index (VPI) değeri ((Beğenme oranı X İzlenme oranı) /100) hesapland1 (12). Videonun kalitesi ve içeriği modifiye DISCERN ölçeği ve Global Quality Scale (GQS) ölçeği kullanılarak mevcut veriler değerlendirildi.

DISCERN ölçeği sağlık hizmetinden yararlanan bireylerin ve bilgi sağlayıcılarının herhangi bir sağlık sorununa yönelik tedavi seçenekler hakkında yazılı bir bilginin kalitesinin değerlendirmesine yardımcı olmak amacıyla tasarlanmıştır. Görsel medya ve bilginin değerlendirilmesi amacıyla ise 5 sorudan oluşan modifiye DISCERN ölçeği kullanılmaktadır (11). Tüm videolar modifiye DISCERN ölçeği kullanılarak içerikte yer alan bilgilerin güvenilirliği ve bütünlüğü açısından değerlendirildi (13). Videoda yer alan bilginin güvenilirliği 1 ile 5 arasında puanlandı (Tablo 1). Videoların kalitesi için kullanılan Global Quality Scale (GQS) ölçeğinde puanlama 1 ile 5 arasında değişmekte olup 1-2 puan düşük kalite, 3 puan orta kalite, 4-5 puan ise yüksek video kalitesinin göstergesidir (Tablo 2) $(11,13)$.

Çalışmada herhangi bir insan ve hayvan verisi kullanılmadığından ve YouTube'da halka açık olarak yayınlanan videolar kullanıldığından dolayı, benzer diğer çalışmalarda da olduğu gibi etik kurul başvurusu yapılmadı (14-16).

Veriler SPSS 17.0 paket programına kaydedildi. Sürekli değişkenler ortalama \pm standart sapma (SD), kategorik değişkenler ise sayı ve yüzdeler ile ifade edildi. Sürekli değişkenlerde grupların ortalamaları arasındaki farkın anlamlılığı için; normal dağılım gösteren gruplarda student $\mathrm{T}$ testi, normal dağılım göstermeyen gruplarda Mann-Whitney U testi kullanıldı. Videoların yükleyen grupların grup içi karşılaştırmalarını değerlendirmek için One-way ANOVA testi kullanıldı. P değerinin 0.05 'den küçük olduğu değerler istatistiksel olarak anlamlı kabul edildi.

Tablo 1. Modifiye DISCERN Ölçeği (Her soru için Evet: 1, Hayir: 0 puan)

\begin{tabular}{cl}
\hline Puan & \multicolumn{1}{c}{ Tanım } \\
\hline $\mathbf{1}$ & Video açık, kısa ve anlaşılır mı? \\
$\mathbf{2}$ & Geçerli kaynaklardan elde edilmiş mi? (Geçerli çalışmalar, \\
$\mathbf{3}$ & Nöroloji uzmanı) \\
$\mathbf{4}$ & Sunulan bilgiler dengeli ve tarafsız mı? \\
$\mathbf{5}$ & Video tartışmalıyici için ek bilgi kayna belirsizlik içeren konuları belirtilmis mi? \\
& değerlendirmiş mi?
\end{tabular}

Tablo 2. GQS (Global Quality Scale) ölçeği

\begin{tabular}{cl}
\hline Puan & \multicolumn{1}{c}{ Tanım } \\
\hline 1 & $\begin{array}{l}\text { Düşük kalitede, sitenin akışı zayıf, çoğu bilgi eksik, } \\
\text { hastalar için hiç kullanışlı değil. } \\
\text { Genel olarak düşük kalitede ve sitenin akışı zayıf. Bazı } \\
\text { bilgiler mevcut ancak birçok önemli konu eksik, } \\
\text { hastalar için çok sınırlı kullanım. }\end{array}$ \\
$\mathbf{3} \quad \begin{array}{l}\text { Orta kalitede, suboptimal akış, bazı önemli bilgiler } \\
\text { yeterince tartışılmış fakat diğerleri yetersiz, hastalar } \\
\text { için kısmen yararlı. }\end{array}$ \\
Kalitesi yüksek ve genel olarak akışı iyi. İlgili bilginin \\
çoğunu içermekte, fakat bazı başlıklar yer almılyor, \\
hastalar için kullanışlı. \\
Kalitesi ve yayın akışı üst düzeyde, hastalar için çok \\
kullanışlı. Tam ve net bilgi veriyor.
\end{tabular}

\section{Bulgular}

Çalışmamızda YouTube'da İngilizce ve Türkçe yayınlanan toplam 120 videoyu inceledik. Videoların kaynağının dağılımı Şekil 1'de gösterildi. İngilizce yayınlanan videoların büyük bölümünün (\%55) sağlık kuruluşları tarafından yüklendiği, Türkçe yayınlanan videoların ise büyük bölümünün (\%31.7) TV kanalları tarafından yüklendiği görüldü.

Herhangi bir yayınlanma süre sinırlaması yapmadığımız Türkçe ve İngilizce yayınlanan videoların yayınlanmaya başladıktan sonraki 


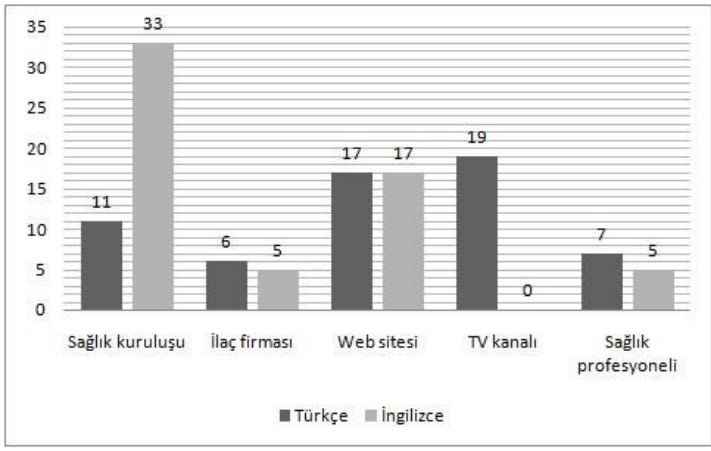

Şekil 1. Videoları yükleyen kaynakların dağılımı

ortalama gün sayıları benzerdi ( $\mathrm{p}=0.472)$. Videoların beğenme oranları da birbirine yakın olarak bulundu $(p=0.545)$. İngilizce yayınlanan videolardaki süre ortalamaları Türkçe yayınlanan videolardan daha uzundu $(p<0.001)$. Türkçe yayınlanan videoların izlenme sayıları $(\mathrm{p}<0.001)$, yorum sayıları $(p<0.001)$, izlenme oranları $(p<0.001)$, beğenmeme $(p<0.001)$ ve beğenmeme $(p<0.001)$ sayılarının ortalamaları İngilizce videolara göre istatistiksel olarak anlamlı derecede düşüktü (Tablo 3). Videoların kalitesini karşılaştırdığımız ölçekleri incelediğimizde VPI $(\mathrm{p}<0.001)$ değeri, GQS $(p<0.001)$ ve modifiye DISCERN ölçeği $(p<0.001)$ puanlarının İngilizce yayınlanan videolarda Türkçe yayınlanan videolara göre anlamlı derecede yüksek olduğu tespit edildi (Tablo 3).

YouTube'da değerlendirilen videoları yayınlayan kaynakları kendi aralarında karşılaştırdığımızda GQS ( $p=0.008)$ ve Modifiye DISCERN $(p=0.023)$ puanlarında anlamlı fark olduğu tespit edildi. GQS puanlarının ortalamaları sağlık kuruluşu tarafından yüklenen videolarda $(\mathrm{GQS}=3.16 \pm 0.91)$, TV kanalı tarafindan yüklenen videolara $(\mathrm{GQS}=2.37 \pm 0.83)$ göre anlamlı olarak daha yüksekti $(\mathrm{p}=0.012)$. Benzer şekilde modifiye DISCERN puanlarının ortalamaları sağlık kuruluşu tarafindan yüklenen videolarda (Modifiye DISCERN=3.14 \pm 1.07$), \quad$ TV kanalı tarafindan yüklenen videolara (mod-DISCERN:2.26 \pm 0.87 ) göre anlamlı olarak daha yüksekti $(\mathrm{p}=0.012)$, (Tablo 4).

\section{Tartışma}

İnternette yer alan videolarla ilgili yapılan çalışmalarda JAMA ve DISCERN gibi yazılı bilimsel materyalin değerlendirilmesi için kullanılması önerilen ölçekler kullanılmakta olup video gibi görsel yayınların değerlendirilmesi için uygun metodoloji ve ölçeklerin geliştirilmesi önerilmektedir (17). Bu nedenle biz çalışmamızda Video power index (VPI) değeri, Global Quality Scale (GQS), ve modifiye DISCERN ölçeğini kulland1k.

Dijital uygulamaların hızlı bir şekilde hayatımıza girmesi ile YouTube gibi platformlar, özellikle pandemi sürecinde geniş kitlelere ücretsiz ulaşabilen tıbbi bilgi kaynağı haline geldi. Yüksek kaliteli videoların yanı sıra, pandemi süresince yanıltıcı bilgilere neden olabilecek düşük kaliteli videoların mevcut olması nedeniyle üniversiteler, akademisyenler, uzman doktorlar gibi güvenilir kaynakların yayınladığı videoların ön planda tutulması gerekir (15).

Bağımsız kullanıcıların eklediği videoların sağlık profesyonellerinin eklediğine göre daha düşük kalitede olması YouTube'da tıbbi bilgi içeren videoların kaynağının önemini ortaya koymaktadır (18). Yapılan çalışmalarda kâr amacı gütmeyen kuruluşlar ve akademik kaynaklı videoların bilgilendirme için en yüksek değerlere sahip olduğu bulunmuş ancak bu videoların toplam içindeki payı $\%$ 12.7, toplam izleyici içindeki payı \%13.4 bulunmuştur. Kullanışlı olarak tanımlanan videolar gibi yanıltıc1-yetersiz bilgi içeren videoların da yüksek beğeni alabildiği görülmektedir (11). İnternet ortamında sağlık ile ilgili video izleyenlerin büyük bir bölümünün ise videonun kaynağı ile ilgilenmediğini gösteren çalışmalar da mevcuttur (19).

İngilizce yayınlanan videoların büyük bölümünün (\%55) sağlık kuruluşları tarafından yüklenmiş olmasına karşılık Türkçe yayınlanan videoların büyük bölümünün (\%31.7) TV kanalları tarafından yüklenmiş olmasının, değerlendirme ölçekleri olan VPI $(p<0.001)$, GQS $(p<0.001)$ ve modifiye DISCERN ölçeği $(\mathrm{p}<0.001)$ puanlarının ortalamalarının İngilizce yayınlanan videolarda Türkçe yayınlanan videolara göre anlamlı derecede yüksek olmasına neden olduğunu tespit ettik.

Çalışmamızda değerlendirilen YouTube videolarının Alzheimer Hastalığı'nın semptomları, nedenleri ve tedavisinin yanı sıra, hastanın yaşam kalitesi ve hasta yakınına destek gibi birçok konuyu içerdiğini gördük. Ayrıca hastalık için risk faktörleri, koruyucu etkenler gibi özellikler de videolarda yer almaktaydı. Az sayıda video erken tanı ve taramadan bahsetmekteydi.

Alzheimer Hastalığı'nın semptomları, tedavisi, koruyucu ve risk faktörlerinin yer aldığ 1 videoların, yaşam kalitesi ve hasta bakımı konusunu içeren videolara göre daha az izlem sayısı olduğu ifade edilmektedir. Daha önceki çalışmalarda da erken tanı ve taramanın videolarda daha az siklıkta bahsedildiği belirtilmektedir. Alzheimer Hastalığ hastası ve hasta yakınlarının tecrübelerinin aktarıldığı videoların YouTube kullanıcıları tarafindan daha fazla oranda tercih edildiği de aktarılmaktadır (20). Yine hasta ve hasta yakınlarının tecrübelerinin aktarıldığı videoların daha çok tercih edildiği sonucuna varan çalışmalarda sağlık bilgilendirmesi konusunda yapılan videoların, sağlık profesyonelleri tarafından, sözü edilen tecrübeleri aktaracak şekilde hazırlanmasının daha faydalı olacağı ifade edilmektedir $(21,22)$. Bu nedenle sağlık konusunda yetkili kamu ve akademik 
kuruluşların YouTube'da yer alan videoların içeriği ve kalitesi üzerinde daha fazla yol gösterici ve denetleyici olması gerekir (23).

Türkçe videolarda genel gözlem olarak görüntü/yayın kalitesinin iyi olmasına rağmen içeriği yetersiz videolar mevcuttu. Dolayısıyla video kalitesi ile içeriğin bir arada değerlendirildiği GQS ölçeğinde puanlama yapmanın çok sağlıklı olmadığını, modifiye DISCERN ölçeğinde de izleyiciler için ek bilgi kaynaklarının belirtilmesi ve belirsizlik içeren, tartışmalı konuların sorgulanmasının da yüksek kalitede ve içeriği izleyenler için oldukça yararlı videoların düşük puan almasına neden olduğunu değerlendirdik. Türkçe ve İngilizce olarak eğitim amaçlı hazırlanan videolarda sağlık profesyonellerine yönelik olarak oldukça spesifik akademik bilgilerin yer alması modifiye DISCERN skorunun düşük olmasına neden olmakla birlikte videolar hasta yakınları için de nitelikli bilgi içermekteydi.

Ulusal ve bölgesel yayın yapan televizyon kanallarında yayınlanan Türkçe videolarda

Tablo 3. Türkçe ve İngilizce yayınlanan videoların karşılaştırılması
Alzheimer Hastalığı hakkında sınırlı, yetersiz ve kısmen de hatalı bilgi verilmesi hastalığın tedavisi için bilimsel olarak geçerliliği gösterilmemiş alternatif tıp yöntemlerinin yer almasının ölçeklerden elde edilen puanların düşük olmasının bir diğer nedeni olduğu sonucuna vardık.

İngilizce videolarda da hasta yakınları ve hastalık hakkında bilgi edinmek isteyenler için mevcut videolarda hastalık tanısı, genetik özellikleri, tedavisi gibi birçok konu yer almaktaydı. Özellikle akademik sağlık kurumları tarafından hazırlanan videolar hastalık hakkında bilgi edinmek isteyen kişiler ve hasta yakınları için oldukça başarılıydı ve ölçeklerden yüksek puanlar aldı. İngilizce videolarda Türkçe videolardan farklı olarak hastalar, yakınları ve sağlık profesyonellerin yer aldığı, hasta bakımı ve günlük yaşam aktivitelerinin konu edildiği videolar, hastalığ videolar bulunmaktaydı.

\begin{tabular}{lccc}
\hline & Türkçe $( \pm$ SD) & İngilizce $( \pm$ SD) & p değeri* \\
\hline Süre (dakika) & $5.88 \pm 6.90$ & $13.05 \pm 19.07$ & $<0.001$ \\
Yayın gün sayısı & $1480.33 \pm 874.09$ & $1680.67 \pm 1130.80$ & 0.472 \\
İzlenme sayısı & $22227.33 \pm 62574$ & $268553.20 \pm 642961.37$ & $<0.001$ \\
Like/Beğenme sayısı & $417.30 \pm 2444.48$ & $1894.10 \pm 3630.13$ & $<0.001$ \\
Dislike/Beğenmeme sayısı & $8.17 \pm 16.64$ & $76.80 \pm 209.60$ & $<0.001$ \\
Yorum sayısı & $18.52 \pm 100.60$ & $184.92 \pm 434.13$ & $<0.001$ \\
Beğenme oranı & $92.83 \pm 14.93$ & $95.53 \pm 3.96$ & 0.545 \\
İzlenme oranı & $14.92 \pm 42.48$ & $235.79 \pm 680.35$ & $<0.001$ \\
VPI & $14.31 \pm 42.17$ & $226.31 \pm 652.73$ & $<0.001$ \\
GQS puanı & $2.60 \pm 0.92$ & $3.37 \pm 0.71$ & $<0.001$ \\
Modifiye DISCERN puanı & $2.30 \pm 0.87$ & $3.27 \pm 0.90$ & $<0.001$ \\
\hline
\end{tabular}

* Mann Whitney U testi

Tablo 4. Videoları yükleyen kaynağa göre GQS ve Modifiye DISCERN puanlarının karşılaştırılması (One-way ANOVA testi)

\begin{tabular}{|c|c|c|c|c|c|c|c|}
\hline & & $\begin{array}{c}\text { Karelerin } \\
\text { toplamı }\end{array}$ & df & $\begin{array}{c}\text { Karelerin } \\
\text { ortalaması }\end{array}$ & $\mathbf{F}$ & p değeri & $\begin{array}{c}\text { Fark } \\
\text { *Hochberg's GT2, } \\
* * \text { Games-Howell }\end{array}$ \\
\hline \multirow{2}{*}{ GQS } & Gruplar arası & 11.092 & 4 & 2.773 & 3.671 & 0.008 & $1-2 *$ \\
\hline & Grup içi & 86.875 & 115 & 0.755 & & & \\
\hline \multirow{2}{*}{$\begin{array}{l}\text { Modifiye } \\
\text { DISCERN }\end{array}$} & Gruplar arası & 11.230 & 4 & 2.807 & 2.958 & 0.023 & $1-2 * *$ \\
\hline & Grup içi & 109.137 & 115 & 0.949 & & & \\
\hline
\end{tabular}

1.Sağlık Kuruluşu, 2. TV kanalı; *Homojen dağılım gösteren GQS puanlarının ortalamalarının Post Hoc analizi için Hochberg’s GT2,

** Homojen dağılım göstermeyen Modifiye DISCERN puanlarının ortalaması için ise Games-Howell testi kullanıldı. 
Çalışmamızda YouTube kanalında "Alzheimer Hastalığı/Alzheimer's Disease" başlığında Türkçe ve İngilizce yayınlanan videoları inceledik ki bu çalışma Türkiye'de bu konuda yayınlanan ilk çalışmadır. Çalışmamızda YouTube kanalında Türkçe ve İngilizce olarak yayınlanan videoları kendi arasında ve karşılaştırmalı olarak değerlendirdik. Ancak sağlık ile ilgili bilgilendirme yapılan diğer kanalları, Web sitelerini değerlendirmemiş olmak, "demans (dementia)", "bunama (cognitive decline)", "Alzheimer" gibi birbiri ile bağlantılı konularda da YouTube videolarını incelememiş olmak çalışmamız için bir eksiklik olarak değerlendirilebilir

Alzheimer Hastalığı ile ilgili olarak hazırlanan ve internet ortamında halka açık olarak Türkçe yayınlanan bilgilendirici videoların kaliteli, hedef kitlenin beklentisini karşılayacak, doğru ve kesin bilgiler içermesi, konusunda uzman hekimlerin yanı sira akademik kurumlar tarafindan toplumun beklentisini karşılayan, özellikle hasta ve yakınlarının tecrübelerini içerecek şekilde hazırlanmasının daha yararlı olacağını düşünmekteyiz.

\section{Kaynaklar}

1. Lopez JS, González HM, Léger GC. Alzheimer's disease. In: Aminoff MJ, Boller F, Swaab DF. Handbook of Clinical Neurology. Chapter 13;2019;167:231-255. Amsterdam: Elsevier.

2. Lane CA, Hardy J, Schott JM. Alzheimer's disease. Eur J Neurol. 2018;25(1):59-70.

3. Alzheimer's Association. 2017 Alzheimer's disease facts and figures. Alzheimers Dement. 2017;13(4):325-73.

4. Kang S, Lee YH, Lee JE. Metabolism-centric overview of the pathogenesis of Alzheimer's disease. Yonsei Med J. 2017;58(3):479-88.

5. Mucke L. Neuroscience: Alzheimer's disease. Nature. 2009;461:895-97.

6. Mayeux R, Stern Y. Epidemiology of Alzheimer Disease. Cold Spring Harb Perspect Med. 2012;2: a006239.

7. Silva MVF, Loures CMG, Alves LCV, et al. Alzheimer's disease: risk factors and potentially protective measures. $\mathbf{J}$ Biomed Sci. 2019;26(1):33.
8. Baumgart M, Snyder HM, Carrillo MC, et al. Summary of the evidence on modifiable risk factors for cognitive decline and dementia: a population-based perspective. Alzheimers Dement. 2015;11(6):718-26.

9. Institute of Medicine. Cognitive aging: progress in understanding and opportunity for action. Washington, DC: The National Academic Press; 2015.

10. Fox S, Purcell K. Chronic disease and the internet. Pew Internet \& American Life Project, Washington, DC, March 2010.

11. Singh AG, Singh S, Singh PP. YouTube for information on rheumatoid arthritis-a wakeup call? J Rheumatol. 2012;39(5):899-903

12. Van den Eynde J, Crauwels A, Demaerel PG, ve ark. YouTube Videos as a Source of Information About Immunology for Medical Students: Cross-Sectional Study. JMIR Med Educ. 2019;5(1):e12605.

13. Bernard A, Langille $\mathrm{M}$, Hughes $\mathrm{S}$, et al. A systematic review of patient inflammatory bowel disease information resources on the World Wide Web. Am J Gastroenterol. 2007:102:2070-7.

14. Health Research Authority. http://www.hradecisiontools.org.uk/research/ Accessed August 21, 2018.

15. Koçyiğit BF, Akaltun MS, Şahin AR. YouTube as a source of information on COVID-19 and rheumatic disease link. Clin Rheumatol. 2020:1-6.

16. Nason GJ, Kelly P, Kelly ME, ve ark. YouTube as an educational tool regarding male urethral catheterization. Scand J Urol. 2014:49(2):189-92.

17. Azer SA. Are DISCERN and JAMA Suitable Instruments for Assessing YouTube Videos on Thyroid Cancer? Methodological Concerns. J Cancer Edu. 2020;35:1267-77.

18. Şahin A, Şahin M, Türkcü FM. YouTube as a source of information in retinopathy of prematurity. Ir J Med Sci. 2019;188(2):613-17

19. Fox S. Online health search 2006. Pew Internet and American Life Project. [Internet. Accessed January 26, 2012.] Available from: http://www.pewinternet.org/Reports/2006/Online-HealthSearch-2006.aspx

20. Tang W, Olscamp K, Ki Choi S, et al. Alzheimer's Disease in Social Media: Content Analysis of YouTube Videos . Interact J Med Res. 2017;6(2):e19.

21. Nestor PJ, Scheltens P, Hodges JR. Advances in the early detection of Alzheimer's disease. Nat Med. 2004;10:34-41.

22. Friedman DB, Laditka JN, Hunter R, et al. Getting the message out about cognitive health: a cross-cultural comparison of older adults' media awareness and communication needs on how to maintain a healthy brain.Gerontologist. 2009;49(1):50-60

23. Madathil KC, Rivera-Rodriguez AJ, Greenstein JS, et al. Healthcare information on YouTube: A systematic review. Health Informatics J. 2015;21(3):173-94. 